\title{
Onychomadesis secondary to autoimmune thyroid disease mimicking thyroid acropachy
}

\section{Ahu Yorulmaz, Basak Yalcin}

\author{
Department of Dermatology, Ankara Bilkent City Hospital, Ankara, Turkey
}

Corresponding author: Dr. Ahu Yorulmaz, E-mail: ahuyor@gmail.com

\begin{abstract}
Onychomadesis has been described as proximal separation of the nail plate from the nail matrix due to drastic insult to the matrix that induces a total arrest of matrix activity. A vast variety of health conditions, mainly including infections and autoimmune diseases have been implicated in the etiology of onychomadesis. However, up to now no published data is available on the association of autoimmune thyroid disease with onychomadesis. Here, we present a case of autoimmune thyroid disease induced onychomadesis in a 85-year-old woman. Moreover, we highlighted a distinct feature of the patient in that nail findings of the patient exceptionally resemble thyroid acropachy, which is a very rare manifestation of autoimmune thyroid disease.
\end{abstract}

Key words: Onychomadesis; Autoimmune thyroid disease; Acropachy

\section{INTRODUCTION}

Onychomadesis is characterized by spontaneous detachment of the nail plate from the nail matrix, in which detachment begins at the proximal end of the nail bed, although not always, consequently leading to nail shedding. A vast variety of health conditions, mainly including infections and autoimmune diseases have been implicated in the etiology of onychomadesis $[1,2]$. It is well-known that thyroid diseases have significant cutaneous manifestations, some of which are distinctly linked with nails [3]. Thyroid acropachy is the utmost cutaneous manifestation of autoimmune thyroid disease, which is characterized by clubbing of fingers and toenails, swollen digits along with subperiosteal new bone formation [4-10]. Here, we describe a patient with onychomadesis associated with autoimmune thyroid disease, whom clinical features mimic those of thyroid acropachy. To our knowledge, this is the first case to be published in which the clinical findings favored the diagnosis of onychomadesis associated with autoimmune thyroid disease.

\section{CASE REPORT}

A 85-year-old woman visited our department with a history of nail shedding in her fingernails and deformation in her toenails. She told that a couple of weeks ago two of her fingernails and a small part of her left big toenail had lifted and subsequently shed with accompanying subtle pain. Her medical history revealed long-standing hypertension, for which she was receiving candesartan/hydrochlorothiazide for years. There was not any history of trauma or precipitating factors preceeding the nail findings. She denied any family history of similar lesions. Upon dermatological examination, we observed anonychia of left middle finger and right ring finger, also proximolateral quadrant of the left big toenail was seperated from the nail bed. All toenails except right $3-5^{\text {th }}$ toenails were dystrophic with subungual hyperkeratosis (Figs. 1 and 2). A dusky erythema in distal parts of foot digits was also noticed (Fig. 1). Dermoscopic examination of toenails revealed subungual hyperkeratosis and purple to black pigmentation corresponding subungual hemorrhage in right $1^{\text {st }}, 2^{\text {nd }}$ and left $1-3^{\text {rd }}$ toenails (Fig. 3). Mycological

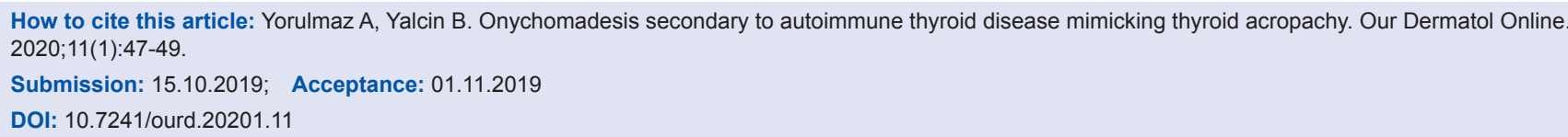




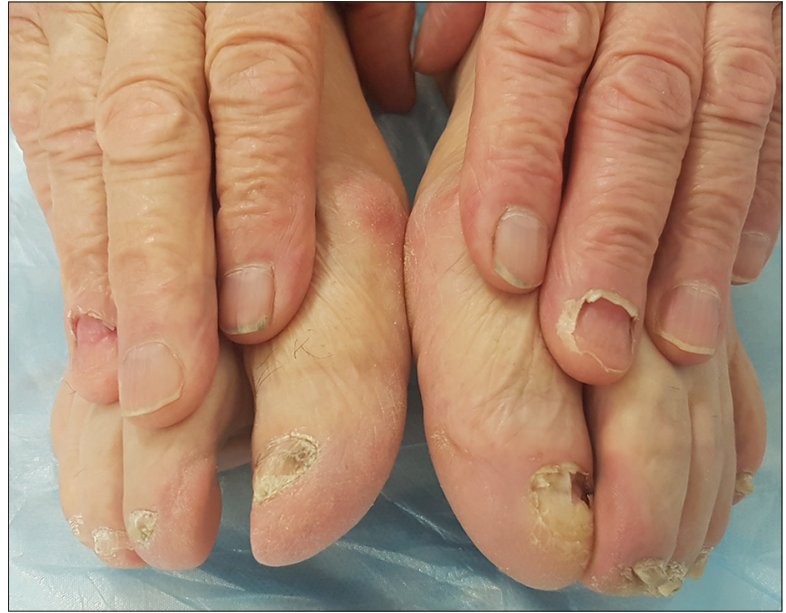

Figure 1: Anonychia of left middle finger and right ring finger, partial loss in left big toenail, subungual hyperkeratosis on toenails. Note the dusky erythema on distal parts of toe digits extending onto the toe pulp.

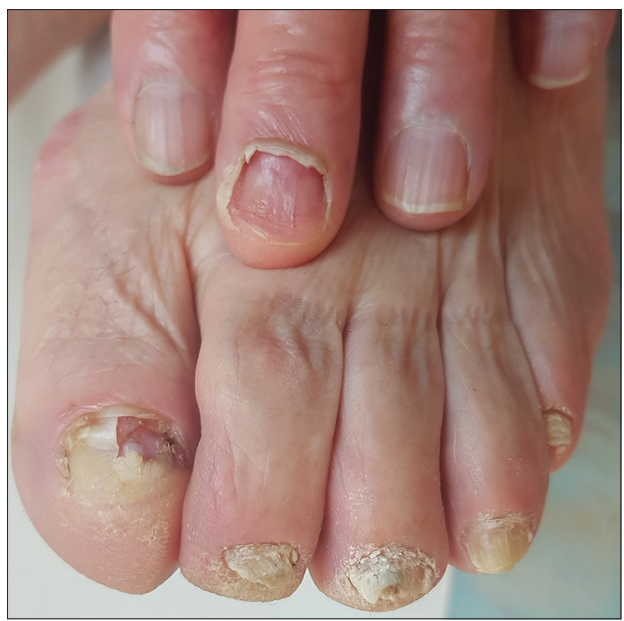

Figure 2: Closer view of left hand and foot. Note onychorrhexis of fingernails and subungual hemorrhages on toenails

examination of toenails was negative. Laboratory studies including biochemical panel, complete blood and differential counts, erythrocyte sedimentation rate, serum ferritin, folate, vitamin B12 and vitamin D levels were normal. The serum thyroid stimulating hormone level was $5.78 \mathrm{mIU} / \mathrm{L}$ (normal range, 0.55 to 4.78 ) and anti-thyroid peroxidase (anti-TPO) was $80 \mathrm{IU} / \mathrm{ml}$ (normal, <60 IU/mL). Anti-nuclear antibody, anti-double stranded DNA antibody, antibodies to saline-extracted antigens (ENA panel) and rheumatoid factor were negative. Plain X-ray radiographic examination of hand and foot were normal. The thyroid ultrasound showed a diffusely enlarged, hypo echoic gland. Thus, based on history and clinical and radiological findings, a diagnosis of onychomadesis associated with autoimmune thyroid disease was established. The patient was referred endocrinology department but lost follow-up after referral.

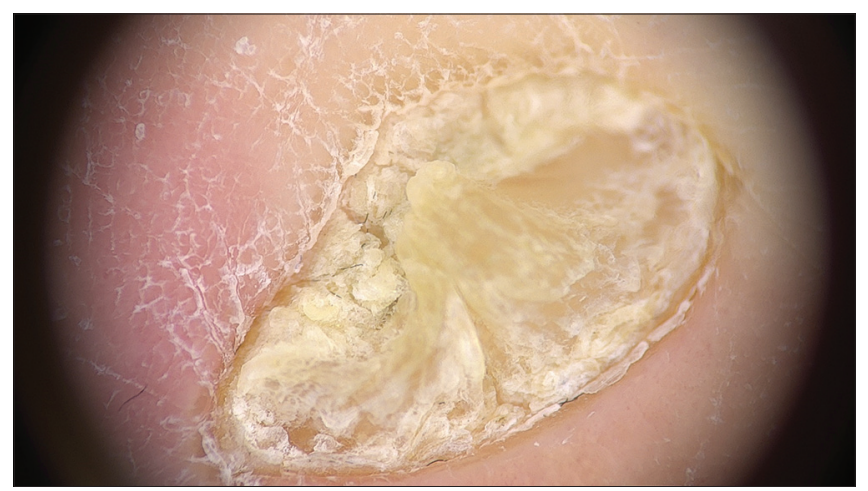

Figure 3: Dermoscopy of right second toenail (FotoFinderx20).

Informed consent was obtained from the patient.

\section{DISCUSSION}

Thyroid acropachy is an uncommon manifestation of autoimmune thyroid disease, characterized by clubbing of finger and toenails, swollen digits along with subperiosteal new bone formation. Other manifestations of autoimmune thyroid disease include thyroid ophthalmopathy and pretibial myxedema, which is also called as thyroid dermopathy. Thyroid acropachy is regarded as the insignificant manifestation of autoimmune thyroid disease, as it has been reported that about $4 \%$ of patients with thyroid ophthalmopathy have dermopathy, and that one of five patients with thyroid dermopathy has acropachy. Although the exact pathogenesis of autoimmune thyroid disease has not been fully understood yet, it is thought that genetic predisposition and environmental factors interact to produce an abnormal immune response to selfantigens. Since the musculoskeletal system is one of the main target tissues for thyroid hormones, autoimmunity against the tyhroid antigens expressed in the connective tissue cells is regarded to be the fundamental process contributing the development of acropachy, which eventually leads to increased glycosaminoglycan and fibroblast proliferation. Thyroid acropachy can be seen in all forms of autoimmune thyroid disease, thus clinically patients may be euthyroid, hypothyroid or hyperthyroid. But, the distinctive feature of thyroid acropachy is that, it represents the most extreme form of tissue damage caused by thyroid autoimmunity, since the presence of acropachy is known to indicate the severity of both ophthalmopathy and dermopathy. Usually, acropachy occurs in patients with long-term Graves' disease, in whom thyroid ophthalmopathy and dermatopathy have already been confirmed. It is suggested that there is a sequential presentation of extrathyroidal manifestations of autoimmune thyroid disease, in which acropachy develops at the last stage. On the other hand, isolated 
case reports of acropachy have been documented in the literature [4-10].

Onychomadesis is considered as the drastic form of Beau's lines, which is defined as the detachment of the nail plate from the proximal nail fold as a result of transitory arrest in the activity of the nail matrix. Onychomadesis has been associated with a wide variety of clinical conditions, including major medical illnesses, infections and autoimmune diseases. Chemotherapeutics, antiepileptics, retinoids, lithium and antibiotics have been also implicated in the etiology of onychomadesis. Among the autoimmune diseases, pemphigus vulgaris is well-known to be associated with onychomadesis, indeed onychomadesis is the most common nail abnormality seen in pemphigus vulgaris $[1,2]$. Here, we described a patient with onychomadesis associated with autoimmune thyroid disease. As far as we know, there is not any report in the literature describing a causal relationship of onychomadesis with autoimmune thyroid disease. Takasu et al. reported a patient with TSBAbpositive hypothyroidism and onycholysis, which is also called as Plummer's nail [11]. Although clinically they are separate conditions, characteristic early finding of onychomadesis is symmetric proximal onycholysis [1]. All the potential etiological factors that could be implicated in the development of onychomadesis in our patient have been excluded. On the other hand, the induration and erythema in the distal parts of the feet (Fig. 1) point to the possible involvement of subcutaneous tissues, which suggests acropachy. However, a negative conventional radiograph, absence of fusiform soft tissue swelling, which usually involves the middle aspects of the digits, also digital clubbing rule out the diagnosis of acropachy. Moreover, although isolated cases of acropachy have been described, it is well-known that acropachy is almost always associated with dermopathy and ophthalmopathy [8].

Here, we report a case with autoimmune thyroid disease, of whom clinical manifestations imply thyroid acropachy, but indeed associated with onychomadesis. We highlight the importance of considering all the etiological factors while evaluating a patient with a nail finding. Since, a minor detail may be major indicator for a serious disease.

\section{CONCLUSION}

Here, we report a case with autoimmune thyroid disease, of whom clinical manifestations imply thyroid acropachy, but indeed associated with onychomadesis. We highlight the importance of considering all the etiological factors while evaluating a patient with a nail finding. Since, a minor detail may be major indicator for a serious disease.

\section{Consent}

The examination of the patient was conducted according to the Declaration of Helsinki principles.

The authors certify that they have obtained all appropriate patient consent forms. In the form the patient(s) has/have given his/her/their consent for his/her/their images and other clinical information to be reported in the journal. The patients understand that their names and initials will not be published and due efforts will be made to conceal their identity, but anonymity cannot be guaranteed.

\section{REFERENCES}

1. Hardin J, Haber RM. Onychomadesis: literature review. Br J Dermatol. 2015;172:592-6.

2. Hardin J, Haber RM. Idiopathic sporadic onychomadesis: case report and literature review. Arch Dermatol. 2012;148:769-70.

3. Puri N. A study on cutaneous manifestations of thyroid disease. Indian J Dermatol. 2012;57:247-8.

4. Gutch M, Sanjay S, Razi SM, Gupta KK. Thyroid acropachy: Frequently overlooked finding. Indian J Endocrinol Metab. 2014;18:590-1.

5. Fatourechi V. Thyroid dermopathy and acropachy. Best Pract Res Clin Endocrinol Metab. 2012;26:553-65.

6. Batal O, Hatem SF. Radiologic case study. Thyroid acropachy. Orthopedics. 2008;31:2, 98-100.

7. Koca TT. Association with thyroid disorders and rheumatic diseases: a case report with thyroid acropachy. Turk J Phys Med Rehab. 2015;61:187-9.

8. Fatourechi V, Ahmed DD, Schwartz KM. Thyroid acropachy: report of 40 patients treated at a single institution in a 26-year period. J Clin Endocrinol Metab. 2002;87:5435-41.

9. Kraus CN, Sodha P, Vaidyanathan P, Kirkorian AY. Thyroid dermopathy and acropachy in pediatric patients. Pediatr Dermatol. 2018;35:e371-4.

10. Mathur SK, Sharma BB, Choudhary D, Rao RS, Shibin TS, Singh V. Clubbing in a case of hypothyroidism. J Assoc Physicians India. 2008;56:241.

11. Takasu N, Seki H. Plummer's nails (onycholysis) in a thyroid-stimulation-blocking antibody (tsbab)-positive patient with hypothyroidism. Intern Med. 2018;57:3055-6.

Copyright by Ahu Yorulmaz, et al. This is an open access article distributed under the terms of the Creative Commons Attribution License, which permits unrestricted use, distribution, and reproduction in any medium, provided the original author and source are credited.

Source of Support: Nil, Conflict of Interest: None declared. 